
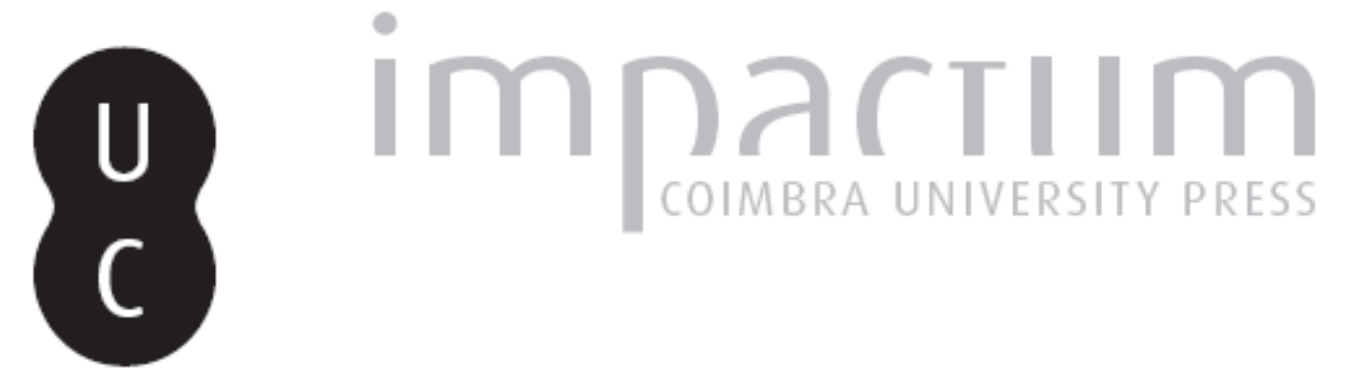

\title{
A propósito da localização de Aranni/Arandis
}

Autor(es): $\quad$ Bernardes, João Pedro

Publicado por: Faculdade de Letras da Universidade de Coimbra

URL persistente:

URI:http://hdl.handle.net/10316.2/37727

DOI:

DOI:http://dx.doi.org/10.14195/1647-8657_45_10

Accessed : $\quad$ 26-Apr-2023 15:41:55

A navegação consulta e descarregamento dos títulos inseridos nas Bibliotecas Digitais UC Digitalis, UC Pombalina e UC Impactum, pressupõem a aceitação plena e sem reservas dos Termos e Condições de Uso destas Bibliotecas Digitais, disponíveis em https://digitalis.uc.pt/pt-pt/termos.

Conforme exposto nos referidos Termos e Condições de Uso, o descarregamento de títulos de acesso restrito requer uma licença válida de autorização devendo o utilizador aceder ao(s) documento(s) a partir de um endereço de IP da instituição detentora da supramencionada licença.

Ao utilizador é apenas permitido o descarregamento para uso pessoal, pelo que o emprego do(s) título(s) descarregado(s) para outro fim, designadamente comercial, carece de autorização do respetivo autor ou editor da obra.

Na medida em que todas as obras da UC Digitalis se encontram protegidas pelo Código do Direito de Autor e Direitos Conexos e demais legislação aplicável, toda a cópia, parcial ou total, deste documento, nos casos em que é legalmente admitida, deverá conter ou fazer-se acompanhar por este aviso.

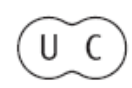




\section{CONIMBRIGA}

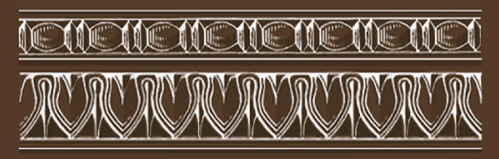

INSTITUTO DE ARQUEOLOGIA

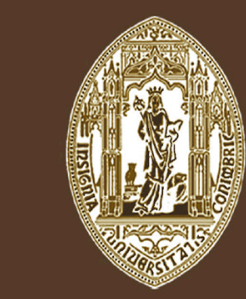

VOLUME XLV - 2006

FACULDADE DE LETRAS UNIVERSIDADE DE COIMBRA 
JoÃo Pedro Bernardes

Departamento de História Arqueologia e Património

Universidade do Algarve

\section{A PROPÓSITO DA LOCALIZAÇÃO DE ARANNI / ARANDIS \\ "Conimbriga" XLV (2006) p. 153-164}

Resumo: Referida nas fontes clássicas, a localização de Aranni ou Arandis, ainda não foi cabalmente esclarecida. Aquelas fontes dizem-nos que a capital dos Aranditani se situava entre Ossonoba e Pax Iulia, constituindo uma estação intermédia na via do itinerário antoniniano que ligava estas duas cidades. Desde Leite de Vasconcelos que se têm proposto localizações diversas para esta importante povoação romana que, necessariamente, se situaria num dos actuais concelhos fronteiriços entre o Alentejo e o Algarve. Discutindo os argumentos das referidas localizações propostas e recorrendo aos dados arqueológicos, literários e históricos disponíveis, procura-se demonstrar a localização deste oppidum situado a 60 milhas de Ossonoba.

RéSumÉ: La localisation de l'oppidum de Aranni ou Arandis, que les auteurs classiques mentionnent, n'est pas encore éclairée. Le lieu central des Aranditani, d'accord les classiques, était situé entre Ossonoba et Pax Iulia. Il était une station intermédiaire sur la voie de l'Itinéraire Antonin que faisait la liaison de ces deux villes. Depuis Leite de Vasconcelos, au XIX Siècle, qu'on a proposé plusieurs localisations pour cet important site romain que, obligatoirement, on doit chercher dans une des communes actuelles de la frontière de la région d'Alentejo e Algarve, au sud de Portugal. On discute les arguments que sont utilisés pour les diverses localisations proposées et, à partir d'informations archéologiques, littéraires e historiques, on essaye de démontrer l'exacte localisation de cet oppidum qu'était situé à 60 milles de Ossonoba. 
(Página deixada propositadamente em branco) 


\section{A PROPÓSITO DA LOCALIZAÇÃO DE ARANNI / ARANDIS}

O Itinerário de Antonino (426.3) situa na via entre Ossonoba e Pax Iulia, vulgarmente conhecida como via 21 , uma estação intermédia a 60 milhas da primeira daquelas cidades a que chama Aranni. A Arani refere-se também o anónimo de Ravena (306.13), certamente com base naquele Itinerário do século III. A povoação é ainda mencionada noutras fontes clássicas, embora com grafia diferente: Ptolomeu (II.5.5) fala em Arandis e Plínio (IV, 118), ao referir-se aos Aranditani, está implicitamente a aludir a um oppidum chamado Arandis e não Aranni (TIR). Tendo em conta que as duas primeiras fontes são tardias e que Plínio e Ptolomeu se situam, respectivamente, nos séculos I e II d.C., talvez que as diferentes grafias possam ser explicadas pela evolução do fonema, com a queda do "d", do Alto para o Baixo Império.

Conhecidas hoje as localizações de Ossonoba em Faro e de Pax Iulia em Beja e dada a distância que medeia entre a primeira daquelas cidades e Arandis que desempenharia funções de mansio no iter antoniniano, tem sido unânime a sua localização no Alentejo. Todavia, já a seu exacto posicionamento é polémico e objecto de diferentes propostas, em grande parte porque no Itinerário se diz que Arandis se localizava a 60 milhas de Faro e a 35 milhas de Alcácer do Sal (Salacia). Ora não é possível que qualquer lugar fique a cerca de 90 quilómetros de Faro e, simultaneamente, a $52 \mathrm{~km}$ de Alcácer do Sal, pelo que há seguramente um erro no Itinerário, como veremos mais adiante. ${ }^{1}$

Em 1960, Abel Viana identifica Arandis com Colos, Santa Luzia ou Garvão circa de Ourique (Viana, 1960:215)². Jorge de Alarcão, se

1 Toma-se como valor métrico da milha romana (m. p.) 1482 m (cf. Sillières, 1990: 59).

2 Aranni, ou Arandis, demoraria cerca de Ourique, talvez Colos, talvez Santa Luzia, talvez Garvão - com maioria de probabilidade esta última... 
inicialmente segue esta proposta (Alarcão, 1974), acaba por se inclinar mais para Garvão em virtude de ali ter aparecido um importante depósito votivo pré-romano (Alarcão, 1985: 103-103; 1988: 52). Segundo este autor, Arandis "deve ter sido não um vicus ou mansio, mas mais do que isso: centro de civitas", cujo território se estenderia pelos actuais concelhos de Ourique, Castro Verde e Odemira (Alarcão, 1985: 104; 1990: 23). Não há, porém, epigrafia ou qualquer outro elemento arquitectónico que suporte a existência de uma capital de civitas na área daqueles concelhos, marcados por escassos e medíocres monumentos epigráficos funerários do século I, o que levará Jorge de Alarcão a admitir a hipótese, ainda que com as cautelas que caracterizam a sua inteligência e argúcia, que "a cidade de Aranni foi uma experiência urbana e administrativa falhada" (Alarcão, 1985: 104).

Parece-nos que não é seguro que Aranni tenha sido centro de civitas, ainda que a aplicação da teoria dos polígonos de Thiessen viabilize a proposta (idem, ibidem). E isto porque consideramos mais que plausível que nem todos os territórios étnicos se teriam convertido em civitates com a reforma administrativa de Augusto, sobretudo quando alguns desses territórios já estariam dependentes de núcleos urbanos cujo estatuto de centralidade, quando não de municipalidade, já estaria definido antes daquela reforma, como parece ter sido o caso de Myrtilis ou Pax Iulia (Alarcão, 1990: 23). A importância do nomen Iulius na região, mais do que indiciar a elevação do oppidum a capital de civitas no tempo de César ou de Augusto, pode antes testemunhar a sua ligação e integração administrativa em qualquer daqueles territoria. Com efeito, a área dos actuais concelhos de Castro Verde, Ourique e Almodôvar, tendo uma forte presença e tradição de ocupação na Idade do Ferro, como é, de resto, comprovado por vários santuários e povoados importantes e ainda por uma tipologia própria de estelas (Fabião, 1998; Encarnação, 1984: 813), perde importância com a época romana, em virtude de emergirem grandes núcleos político-administrativos de forte vocação centralizadora como eram Mértola e Beja. Face à estratégia romanizadora, não justificaria transformar Aranni num centro de civitas com tudo o que isso implicaria em termos de meios e recursos; mas ainda que se queira admitir que tal tivesse acontecido no plano ou intenção política, parece que, na prática, não teria chegado a efectivar-se, ocorrendo a tal experiência urbana e administrativa falhada, de que fala Jorge de Alarcão, traduzida na ausência de padrões de magnificiência urbana que se impunha aos centros de poder regionais. Ou seja, mesmo 
que um povoado central do território dos Aranditani se tenha constituído como capital de civitas de iure, nunca terá atingido esse estatuto de facto. Desta forma cremos que Aranni nunca teria passado de um aglomerado secundário com funções de mansio, desempenhando, eventualmente, algumas funções de gestão politico-administrativa delegadas pela cidade-capital de que dependia: Pax Iulia ou, mais provavelmente, Myrtilis. ${ }^{3}$

Recentemente, Maria e Manuel Maia (2000) propõem Santa Bárbara dos Padrões, no concelho de Castro Verde, como o local onde teve assento a povoação romana do Itinerarium. Tal proposta baseia-se nos vestígios arqueológicos que ali exumaram, com destaque para um importante depósito votivo de lucernas, e ainda por aquela localização se ajustar melhor do que Garvão às tais 60 milhas distantes de Ossonoba de que fala o Itinerário antoniniano. Todavia, não discutem os argumentos que apresentam, pelo que a proposta que avançam ficou por demonstrar. Retomando a ideia já avançada por aqueles autores, discutiremos a sua viabilidade, rejeitando, desde logo, a proposta tradicional da povoação dos aranditani se situar a poente da vila de Ourique.

Com efeito, como bem observaram Maria e Manuel Maia (2000), a distância de Colos, Santa Luzia ou Garvão a Faro, que supera, em qualquer dos casos, as 70 milhas romanas, exclui a possibilidade de Aranni se situar por ali. Os percursos medievais acabam por corroborar a impossibilidade do trajecto da via 21 do itinerário antoniniano apontar a qualquer localidade situada naquelas imediações. Ao contrário, concordam com um traçado viário que se faria mais a leste, pelas imediações de Almodôvar / Santa Bárbara dos Padrões. O caminho de Garvão ao Algarve, que aparece numa doação de 1260 do então concelho de Marachique, e que passa por Corte Figueira ${ }^{4}$, dá-nos uma ideia do percurso e extensão que uma via romana, a existir na altura, teria de Faro a Garvão: cerca de $110 \mathrm{Km}$, ou seja, 74 milhas romanas. Porém, a grande via de ligação norte / sul em pleno século XIII sulcava Almo-

3 A aldeia de Santa Bárbara dos Padrões, que identificamos com Aranni, fica muito mais próxima de Mértola do que de Beja. No século XIII aquela povoação constituía o limite entre os concelhos de Marachique e Mértola. Em 1269, o mestre D. Paio Peres Correia alienou do termo de Mértola a favor de Martim Anes "os lugares dos Padrões no campo de Ourique" conforme se diz em documento da época (Viana, 1960: 201). A não constituir uma civitas autónoma, o território dos Aranditani faria parte, muito provavelmente, da civitas de Myrtilis.

4 IAN/TT, gaveta 12, maço 5, n. ${ }^{\circ} 25$ (publicado por Viana, 1960: 199). 
dôvar e as proximidades de Santa Bárbara dos Padrões, constituindo eventualmente a referência para o limite entre os concelhos de Marachique e Mértola (cf. nota anterior). Era esta, certamente, a antiga via romana que, na Idade Média, constituía ainda uma das principais ligações ao Algarve, de que a ostensiva ponte da época que se vê em Almodôvar constitui um inequívoco testemunho. A importância da via e o papel que desempenhava no trânsito de mercadorias era tal que, em pleno século XV, no tempo de D. Pedro, Almodôvar, a par de Lisboa, Porto, Coimbra e Santarém, constituía um dos principais centros de câmbios do país 5 .

Para além das LX m. p. a que a povoação alentejana dista de Ossonoba, o Itinerário de Antonino indica XXXV m. p. de Aranni a Salacia, distância, como vimos, impossível porque incompatível com o primeiro tramo de 60 milhas a partir de Ossonoba. Onde está o erro? Na enumeração das distâncias? Na das localidades? Ou a Salacia enunciada é outra terra com o mesmo nome da Alcácer do Sal romana?

Considerando as diferentes estações enumeradas na via 21 até Aranni (Baesuris, Balsa, Ossonoba) constatamos que as distâncias apresentadas estão correctas. Aceitando Santa Bárbara dos Padrões como o locus de Aranni, também a distância de Ossonoba até aqui é coincidente, sendo plausível admitir que as restantes distâncias deste iter estejam correctas. A razão para aquele suposto erro deverá, assim, ser outra.

Ainda que se aceite a existência de outras povoações com o nome Salacia, como a que aparece na via XVII do itinerário, elas deveriam, por aquilo que o étimo significa, localizarem-se na orla costeira e nunca em regiões como o interior alentejano ${ }^{6}$. Não será assim muito lógico admitir, sem mais, que qualquer povoação com o nome Salacia se situasse em pleno coração do Alentejo, a XXXV m. p. de Santa Bárbara dos Padrões.

A exactamente 35 milhas de Santa Bárbara dos Padrões fica Beja. Ora situando-se esta localidade do concelho de Castro Verde às distân-

5 Isso mesmo vem referido por Fernão Lopes na Crónica de D. Pedro I, Porto, 1965, p. 54 (cit. por Filipe Themudo Barata, "Negócios e crédito: complexidade e flexibilidade das práticas creditícias (século XV)" Análise Social, Vol. XXXI (131-137), $1996\left(2 .^{\circ}-3{ }^{\circ}\right)$, p. $683-709$ (p. 691, nota 24).

6 A identificação do Cerro da Vila (Vilamoura) com a Salacia da via XIII do Itinerário de Antonino, que a situa a 16 milhas de Ossonoba (Faro), já foi sugerida com base na coincidência da distância de Faro a Vilamoura (Arias, 1987: 300). 
cias exactas de Ossonoba e Pax Iulia referidas no itinerário, temos aqui um forte argumento para a localização de Aranni naquela povoação alentejana a par da convicção de que as distâncias dadas no iter Ossonoba - Pax Iulia estarão correctas. Parece, pois, que o erro do Itinerário não está na distância mas na localidade que se segue a Aranni Salacia em vez de Pax Iulia. O percurso da via de Ossonoba a Pax Iulia, tal como aparece descrito, terá, provavelmente, sido fundido com um outro percurso ou outros tramos que tocavam a capital do Baixo Alentejo, o que explica a inviabilidade do traçado 21 do Itinerário ${ }^{7}$.

É certo que a importância da via e o facto de a Santa Bárbara dos Padrões se ajustar uma distância de 60 milhas a Faro e de 35 milhas a Beja, constituem argumentos fortes para aqui se situar Aranni. Mas existirão no terreno vestígios arqueológicos consentâneos com a localização daquela estação do Itinerário de Antonino?

Em 1897, Leite de Vasconcelos visita a aldeia de Santa Bárbara dos Padrões encontrando abundantes e variados vestígios romanos (Vasconcelos, 1930-1931: 231-232). Na povoação observa, em grande quantidade, enormes pedaços de opus signinum, tijolos e sepulturas em tijolo que lhe parecem romanas. A sudoeste da povoação, refere um imponente muro de alvenaria com quase 3 metros de largura, mais de um metro de altura e que se estendia por 50 metros, tendo encontrado associado ao mesmo um cano de chumbo com 9 metros de comprimento e um palmo de diâmetro. O muro, que classificou como muralha da antiga povoação, poderá, antes, corresponder a uma antiga barragem que, aliás, tem correspondência na tradição local e que estará hoje oculta sob a estrada municipal que conduz às minas de Neves-Corvo (Maia, 1997: 13). Na colina em torno da igreja da povoação, Leite de Vasconcelos detectou sólidos alicerces, colunas e numerosos fragmen-

7 A inviabilidade deste traçado já foi amplamente debatida, tendo daí resultado diferentes propostas para o corrigir (veja-se, por exemplo, Roldán Hervás, 1975; Sillières, 1990; Ruiz Acevedo, 1998). O percurso dado (Esuri - Balsa m. p. XXIIII - Ossonoba m. p. XVI - Aranni m. p. LX - Salacia m. p. XXXV - Eboram m. p. XLIIII Serpa, m. p. XIII - Fines m. p. XX - Arucci m. p. XXV) deverá ser desdobrado em Esuri, Balsa, Ossonoba, Aranni, [Pax Iulia] e em Salacia, Ebora, [Pax Iulia] Serpa, Fines, Arucci, correspondendo este segundo percurso a uma proposta já avançada por Pierre Sillières (1990: 446). Tendo em conta que Ebora é grafado como Eboram, poderíamos admitir que o traçado se lesse neste segundo tramo como "de Pax Iulia para Ebora 45 milhas; a Serpa XIII, a Fines XX, a Arucci XXV”, admitindo-se, neste caso, que Salacia figura, erradamente, no itinerarium em vez de Pax Ivlia. 
tos cerâmicos, incluindo tegulae (Vasconcelos, 1930-1931: 231-232). Alude ainda à parte superior e circular de um poço de opus signinum, junto à igreja, que será mais tarde referido por outros autores (Quintela et. al., 1986: 132). A existência de vestígios arqueológicos significativos no local acaba por ser confirmada por Maria e Manuel Maia, cujas escavações junto à igreja e cemitério permitiram exumar um grande edifício de planta basilical dos séculos IV a VI d.C., que se sobrepunha a tanques de opus signinum de cronologia anterior, e um depósito votivo com milhares de lucernas dos séculos I ao III d.C. (Maia, 1997).

A área arqueológica, porém, não se restringe hoje à zona da igreja e cemitério, estendendo-se pelas vertentes da pequena colina onde está implantado o templo cristão, sobretudo na direcção nascente/poente, numa extensão de 6 a 7 hectares. Por toda esta vasta área vêem-se numerosos fragmentos de cerâmica de construção, muitos dos quais integrados nos muros divisórios de propriedades e de quintais da povoação. Tal extensão de vestígios, a juntar ao extraordinário depósito votivo e demais estruturas exumadas, só pode indiciar a presença de qualquer aglomerado da época romana centrado em torno da colina onde se elevou a igreja, como que a perpetuar o local sagrado pagão que ali existiu. Este aglomerado, secundário em relação às cidades de Myrtilis ou Pax Iulia, pelas características que apresenta e pela localização geográfica, só poderá corresponder a Aranni. Estação viária importante na ligação de Ossonoba a Pax Iulia, esta povoação parece ter-se ainda afirmado como importante lugar de culto ou santuário, funcionalidades essas que se encontram frequentemente associadas. Transposta a serra do Caldeirão, percurso sempre árduo, penoso e cheio de perigos, Aranni oferecia-se como o local de repouso merecido, onde a água era uma constante e o culto aos deuses se impunha, tal como a imagem do destino pacense que se descortinava ao fundo da planície e cuja distância seria vencida na jornada seguinte.

Pelos vestígios conhecidos desde o século XIX podemos ter uma ideia, ainda que vaga, da topografia do povoado (Est. I). No alto da colina, sob a actual igreja conforme já foi proposto (Maia e Maia, 1997:19), encontrava-se o santuário. O empedrado do adro da igreja é constituído por muitas pedras reaproveitadas algumas das quais, apresentando acentuado desgaste, desempenharam diversas funções em vãos de edifícios; ainda no adro vê-se um grande monólito que já foi interpretado como menir (idem) mas que se poderá também interpretar- 
-se como elemento de um entablamento ou lintel de qualquer grande edifício, até pelo entalhe que apresenta num dos lados à maneira de encaixe ou de superfície de apoio sobre outro elemento. Não longe, a servir de base a um cruzeiro, encontra-se outro grande elemento arquitectónico, de mármore, igualmente de imponente edifício, e que parece corresponder a uma base de coluna a que Leite de Vasconcelos já tinha feito alusão (Vasconcelos, 1930/1931: 232).

Desenvolvendo-se pelas vertentes, a povoação, de acordo com os vestígios hoje perceptíveis no terreno, estender-se-ia para poente até à linha de água a partir de onde começam as casas da povoação de Santa Bárbara. Quase na base da vertente, junto ao ribeiro, encontra-se um poço antiquíssimo, cujo restauro recente o desvirtuou, nomeadamente ao retirar-se-lhe o bocal em pedra com sulcos profundos provocados pelo constante passar das cordas dos baldes mergulhados no seu interior. O poço encontra-se rodeado por uma plataforma, hoje refeita, mas onde até há pouco tempo eram visíveis vestígios de opus signinum, que rodeavam pias escavadas na rocha para dar de beber aos animais. Talvez seja este o poço referido por Leite de Vasconcelos ao dizer que "ao pé da igreja vê-se a parte superior de um poço de opus signinum, de mais de 1 metro de diâmetro" (idem).

Transposta a linha de água, situava-se a necrópole, a julgar pelas "sepulturas feitas de tijolo" a que Leite de Vasconcelos (1930/1931: 231) se refere; a sudoeste uma grande barragem, já referida, e construída, ainda segundo aquele autor, em alvenaria (opus incertum), permitiria o armazenamento de grandes quantidades de água necessária à irrigação dos campos, ao abastecimento das populações e termas de que não se conhecem vestígios. Um pouco por todo o lado, nos muros de divisão de propriedades e de quintais das casas da povoação, são abundantes os elementos reutilizados, sobretudo de cerâmica de construção.

Do ponto de vista arqueológico, mas também pelo seu posicionamento geográfico, Santa Bárbara dos Padrões oferece, pois, os melhores argumentos para situar aqui Aranni. A avaliar por aquilo que se conhece, o sítio parece corresponder a um aglomerado secundário enquadrável nos tipos I e II que Michel Mangin e Francis Tassaux (1992: 463-465) definiram para o Sudoeste da Gália. Aqueles tipos são marcados, respectivamente, por apresentarem funções religiosas predominantes ou cuja função primordial estará ligada às vias onde figuram mansiones. 
Toda a região tem uma ampla tradição de ocupação pré-romana, onde abundavam os locais de culto ${ }^{8}$, bem ilustrados, de resto, na exposição que esteve patente ao público no museu da Lucerna de Castro Verde entre 18 de Outubro de 2002 e 28 de Fevereiro de 2003, com o sugestivo título "Encruzilhadas e Santuários". Montel e S. Pedro das Cabeças, só para citar dois sítios próximos e do concelho de Castro Verde, foram dois desses locais de culto organizado durante a Idade do Ferro. Ainda que as manifestações cultuais se tenham mantido aí até à época romana, parece que tendem a decair durante este período. Ao contrário, o sítio de Santa Bárbara dos Padrões assume com a romanidade um lugar central dentro dos santuários da região, como é evidenciado pela deposição de milhares de lucernas. Montel, estrategicamente bem posicionado sobre a ribeira de Cobres de onde era possível controlar os corredores de circulação, foi sede de culto durante o período do Bronze Final e período Romano Republicano. Já S. Pedro das Cabeças é um santuário de altura, parcialmente destruído por terraplenagens em 1979, na sequência das quais, e da intervenção arqueológica que se seguiu, foram recolhidos dezenas de ex-votos de barro da II Idade do Ferro. Apesar de se registarem vestígios da época romana imperial, eles são escassos e pouco significativos ${ }^{9}$. A perda de importância de ambos os locais de culto pré-romanos a favor de Santa Bárbara dos Padrões justifica-se pela passagem da via nesta última localidade onde, até ao momento, não se conhecem vestígios da Idade do Ferro ${ }^{10}$.

Com a reorganização político-administrativa da época romana e a definição ou reafirmação de centralidades e eixos de circulação decorrentes de uma nova lógica da hirerarquização e estruturação do território, é natural que espaços antigos percam a sua primazia a favor de núcleos antes secundarizados ou mesmo inexistentes. Parece assim que

8 A este propósito veja-se o relatório das prospecções e escavcações executado por Maria e Manuel Maia em 1986 e apresentado à Somincor, bem como os seus artigos publicados em Rego, 1996.

9 Destes dois interessantes sítios pré-romanos pouco se conhece. Em S. Pedro das Cabeças Manuel e Maria Maia fizeram uma intervenção de emergência cujos resultados e espólio mais significativos foram publicitados na referida exposição do museu da Lucerna e em Rego, 1996. Foi ainda nestes espaços que aqueles autores apresentaram dados sobre Montel.

10 Junto a N. ${ }^{\text {a }}$ Sr. ${ }^{\text {a }}$ da Graça dos Padrões, localidade próxima de Santa Bárbara, conhecem-se vestígios da Idade do Ferro nos castella de Castelinho dos Mouros e Castelo dos Mestres à vista dos quais deveria passar a via (Fabião, 1998: 271, fig. 8). 
a passagem da via Ossonoba - Pax Iulia por Aranni teria catalizado as tendências cultuais dos locais próximos, aliando a função de estação viária a uma dimensão de local de culto de acordo com uma tendência algo frequente no mundo romano ${ }^{11}$. A continuidade do culto na Antiguidade irá pelo menos até ao século VI, sendo perpetuada até aos dias de hoje com a edificação da Igreja que ali se vê.

\section{REFERÊNCIAS BIBLIOGRÁFICAS}

AlarCão, Jorge (1974) Portugal romano, Coimbra, ed. Verbo.

(1985) "Sobre a romanização do Alentejo e do Algarve", In Arqueologia, n. ${ }^{\circ} 11$, Porto.

(1988) O domínio romano em Portugal, Mem Martins, publicações Europa-América.

(1990) "Identificação das Cidades da Lusitânia", Les Villes de Lusitanie Romaine, Table ronde internationale du CNRS (Talence, le 8-9 décembre 1988), Paris, pp. 21-34.

ARIAS, Gonzalo (1987) Repertorio de caminos de la Hispania Romana, s.l.

EnCarnação, José d' (1984) Inscrições Romanas do Conventus Pacensis. Subsídios Para o Estudo da Romanização, Coimbra.

FABIÃo, Carlos (1998) O Mundo Indígena e a sua Romanização na Área Céltica do

Território Hoje Português, vol. I, Lisboa (dissertação de doutoramento dactilografada).

MaIA, Maria Garcia Pereira (2000) Levantamento da Carta Arqueológica da Freguesia de Cachopo, Tavira, Campo Arqueológico de Tavira.

MAIA, Maria Garcia Pereira e MAIA, Manuel (1997) Lucernas de Santa Bárbara, Castro Verde, Edição Cortiçol.

Mangin, Michel \&. TassauX, Francis (1992) "Les Agglomérations Secondaires de l'Aquitanie Romaine", Villes et Agglomérations Urbaines Antiques du Sud-Ouest de la Gaule (Deuxième Colloque Aquitania: Bordeaux, 13-15 Septembre, 1990), Bordeaux, pp. 461-479.

Quintela, António de Carvalho, Cardoso, João Luís, Mascarenhas, José Manuel (1986) Aproveitamentos Hidráulicos Romanos a Sul do Tejo, Lisboa, Direcção Geral dos Recursos e Aproveitamentos Hidráulicos.

Rego, Miguel L. V. (Dir.) (1996) Mineração no Baixo Alentejo, Castro Verde, ed. da C. M. Castro Verde.

Roldan HeRvás, J. M. (1975) Itineraria Hispana: fuentes antiguas para el estudio de las vias romanas en la Península Ibérica, Valladolid.

11 Veja-se, por exemplo, a este propósito a obra editada por Michel Mangin e Francis Tassaux já referida. 
Ruiz Acevedo, Juan M. (1998) Las Vias Romanas en la Provincia de Huelva, Huelva, Diputación Provincial de Huelva.

Sillières, Pierre, (1990) Les Voies de Communication de l'Hispanie Méridionale, Paris, Publications du Centre Pierre Paris.

TIR = Tabula Imperii Romani, Madrid, 1995, s.v. Arandis, Aranni .

VAsconcelos, José Leite de (1930/1931) "Excursão pelo Baixo-Alentejo - 1897”, O Archeologo Português, XXIX, Lisboa, Imprensa Nacional, pp. 230-246.

VianA, Abel (1960) "Notas Históricas, Arqueológicas e Etnográficas do Baixo Alentejo", Arquivo de Beja, vol. XVII, Beja, pp. 138-231. 


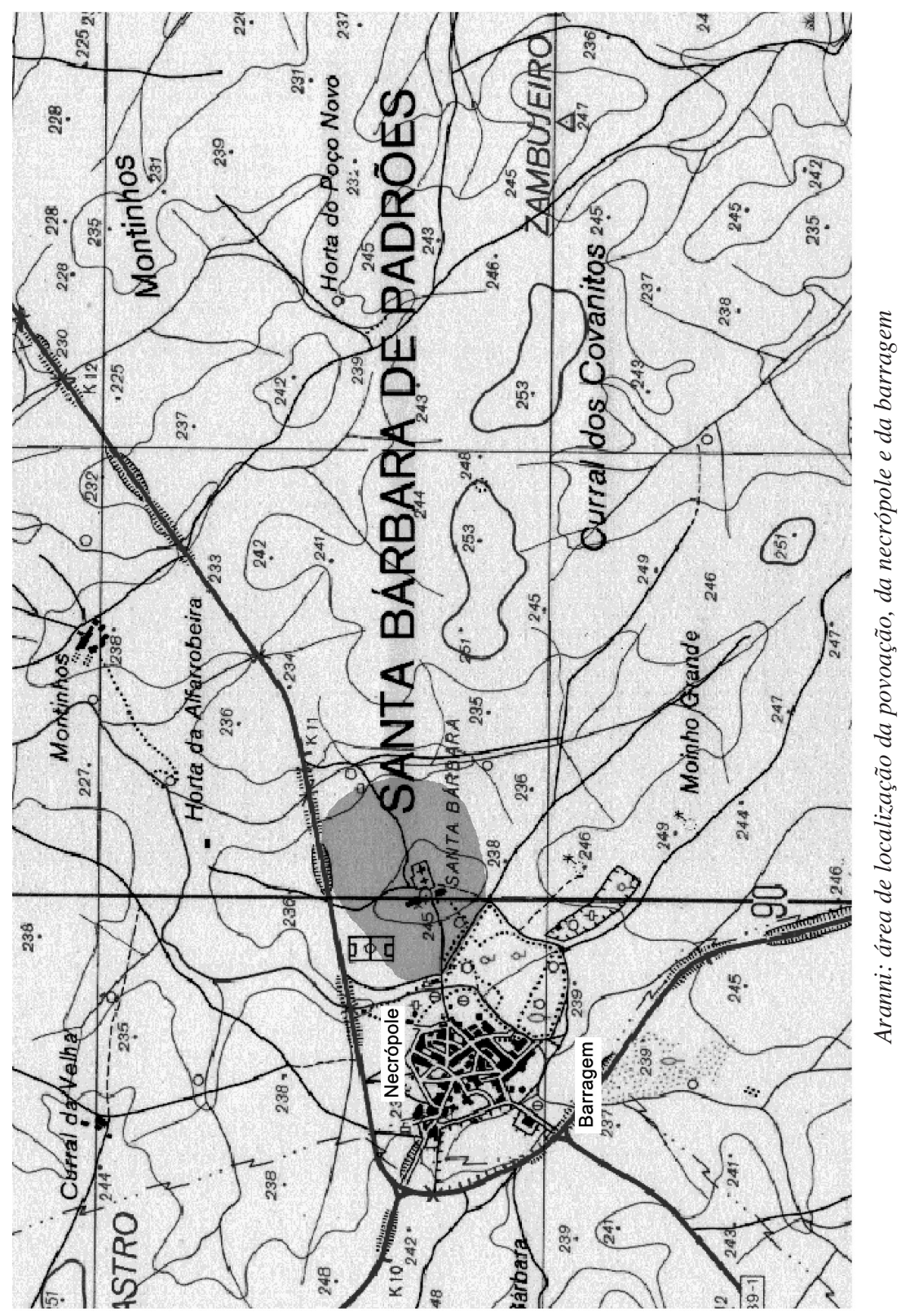

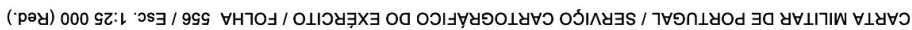

